\title{
Comparison of the Anti-Inflammatory Effects of Artificial Tears in a Rat Model of Corneal Scraping
}

\author{
Philippe Daull, ${ }^{1}$ Laurence Feraille, ${ }^{2}$ Pierre-Paul Elena, ${ }^{2}$ and Jean-Sébastien Garrigue ${ }^{1}$
}

\begin{abstract}
Purpose: Artificial tears (ATs) are used routinely to alleviate the symptoms of mild to moderate dry eye. Preservative-free cationic emulsions (eg, Cationorm ${ }^{\circledR}$ ) are an innovative approach for the management of signs and symptoms of dry eye. The aim of the present exploratory experiment was to evaluate the efficacy of this cetalkonium chloride (CKC)-containing cationic emulsion on debrided cornea and to characterize its effects on scraping-induced inflammation.

Methods: Four ATs were assessed in a rat model of corneal scraping. The upper part of the corneal epithelium was scraped before a 5-day treatment, followed by clinical evaluations and fluorescein staining to evaluate cornea recovery. The anti-inflammatory efficacy of the ATs was assessed in vivo and in vitro.

Results: In vivo confocal microscopy (IVCM) revealed a trend toward better corneal clinical signs (lower IVCM scores) for the animals treated with the unpreserved ATs. Benzalkonium chloride treatment decreased goblet cell count by $37.5 \%$. While the soft-preserved Systane Balance ${ }^{\circledR}$ and Optive ${ }^{\circledR}$ and the preservative-free Vismed ${ }^{\circledR}$ had no effect on the goblet cell count, Cationorm increased this count by almost $40 \%$. Interestingly, inflammatory cell infiltration in the stroma was at its lowest following treatment with the preservative-free Cationorm. Cationorm is also the only AT decreasing IL6- and IL8-stimulated secretion by 59\% and 74\%, respectively.

Conclusion: By restoring an adequately hydrated ocular surface environment, the different ATs promote corneal epithelium healing. These data position Cationorm as a promising AT for the management of signs and symptoms of dry eye in patients with mild to moderate dry eye disease presenting chronic subclinical levels of ocular inflammation.
\end{abstract}

\section{Introduction}

D RY EYE DISEASE (DED) is one of the most prevalent ocular diseases $^{1,2}$ affecting between $5 \%$ and $30 \%$ of people aged more than 50 years, according to Dry Eye WorkShop (DEWS). ${ }^{3}$ In addition, in the Salnes eye study, the prevalence of DED in a Spanish adult population was found to be $11.0 \%,{ }^{4}$ and based on self-reporting of dry eyes in the Beaver Dam Offspring cohort, prevalence of DED was reported at $14.5 \% .^{5}$ The causes of DED are multifactorial ${ }^{6,7}$ and result in symptoms of discomfort, visual disturbance, and ocular pathological changes, including corneal epithelial injury and conjunctival squamous metaplasia. However, DED seems to be invariably associated with chronic inflammation of the ocular surface, although it is not known whether the local inflammation is causative ${ }^{8}$ or simply occurs as a consequence of ocular dryness. ${ }^{9,10}$
Regardless of the level of DED severity, frequent applications of artificial tears (ATs) remain a widely accepted and first-line treatment strategy for close to $80 \%$ of patients. ${ }^{11,12}$ These supplements, depending on their formulation and active ingredients, are intended to (i) expand tear volume in aqueous tear deficiency; (ii) improve symptoms of dry eye in meibomian gland dysfunction patients ${ }^{13}$; and (iii) enhance the tear film (TF) lipid layer of the TF and therefore improve TF stability and reduce tear evaporation. ${ }^{14-16}$

In the AT field, very few compounds have been shown to present biologic anti-inflammatory function. For example, 2 ingredients in ATs, trehalose and hyaluronic acid (HA), have been reported to present some anti-inflammatory efficiency. According to a human study in DED patients, HA suppressed inflammatory markers. ${ }^{17,18}$ In studies using an animal dry eye model, trehalose eye drops reduced proinflammatory cytokine upregulation. ${ }^{19-21}$ Recently, an eye drop formulation

\footnotetext{
${ }^{1}$ Novagali Innovation Center, Santen SAS, Evry, France.

${ }^{2}$ Iris Pharma, La Gaude, France.

(C) Daull et al. 2016; Published by Mary Ann Liebert, Inc. This Open Access article is distributed under the terms of the Creative Commons Attribution Noncommercial License (http://creativecommons.org/licenses/by-nc/4.0/) which permits any noncommercial use, distribution, and reproduction in any medium, provided the original author(s) and the source are credited.
} 
containing alpha-linoleic acid or a combination of the omega3 essentially fatty acid and HA in eye drops has been reported to be effective at decreasing inflammatory cytokines in a murine experimental dry eye model. ${ }^{22,23}$

Cationorm $^{\circledR}$ is a cationic oil-in-water emulsion, in which the positive charges of the oil nanodroplets are brought by cetalkonium chloride (CKC), a lipophilic quaternary ammonium with a 16-carbon aliphatic chain. The low dose and high lipophilicity of CKC prevent it from having either a detergent or a preservative action in Cationorm. ${ }^{24,25}$ It is an AT used in the management of signs and symptoms of dry eye in mild to moderate DED patients. ${ }^{26,27}$

The present study evaluates and compares the efficacy of the cationic oil-in-water emulsion in improving the corneal wound healing process in a corneal debridement rat model ${ }^{28,29}$ with other ATs and its possible role on the modulation of the inflammatory response associated with the debridement procedure. This model is also known to be the most appropriate for looking at cell migration and inflammation. ${ }^{30}$

\section{Methods}

\section{Animals and treatments}

Male Wistar rats (Centre d'élevage Janvier, Le Genest Saint Isle, France), 7-8 weeks of age, were used in these experiments. The Iris Pharma Institute Animal Care and Use Committee approved the protocol, and all animals were treated according to the Association for Research in Vision and Ophthalmology statement for the Use of Animals in Ophthalmic and Vision Research.

Rats were randomly assigned to 7 groups, including a normal control group without any corneal defect. The other groups were subjected to corneal abrasion and received topical treatments with phosphate-buffered saline (PBS), $0.02 \%$ BAK solution (benzalkonium chloride in PBS), Systane Balance ${ }^{\circledR}$ (Alcon Laboratories, Inc.), Optive ${ }^{\circledR}$ (Allergan, Inc.), Vismed ${ }^{\circledR}$ (Horus Pharma), or Cationorm (Santen SAS). Ten microliters of each eye drop was applied twice a day for 5 days in both eyes. The treatments were encoded. The treatment allocation was blinded to the technician administering the treatment, and the researcher assessing the outcome of the experiment was blinded to the treatment allocation. Group identification was uncovered at the end of the analysis. ATs are presented in Table 1 with active ingredients and preservatives.

\section{In vivo rat model of corneal epithelial wound healing}

Rats were deeply anesthetized by intramuscular injection of a mixture of xylazine and ketamine. A drop of $0.4 \%$ oxybuprocaine was topically applied as local anesthesia. Five microliters of a $50 \%$ ethanol solution was applied to the upper cornea of the right eye of each rat for $5 \mathrm{~s}$, after which the corneal epithelium was removed from about $50 \%$ of the corneal surface using a scalpel blade under the operating microscope. Deepithelialization was confirmed by fluorescein staining.

\section{In vivo confocal microscopy}

An HRT II/RCM (Heidelberg Engineering GmbH) was used to examine the animals. The HRT II camera was left connected to the headrest in a horizontal position. The laser source was a diode laser with a wavelength of $670 \mathrm{~nm}$ and the objective of the microscope is an immersion lens, magnification $\times 60$, numerical aperture 0.90 (Olympus). A drop of Gel-larmes (Laboratoires Théa) was placed on the tip of the objective lens to maintain immersion contact between the objective lens and the eye. The anesthetized animals were positioned under the microscope with the central cornea directed perpendicularly to the objective. Images covering an area of $400 \times 400 \mu \mathrm{m}$ with transverse optical resolution of $\sim 2 \mu \mathrm{m} /$ pixel were taken. Oblique sections of the cornea were obtained by manual control. For all eyes, 5 confocal images, including superficial and basal epithelium, anterior and posterior stroma, and endothelium, were recorded.

\section{In vivo confocal microscopy scoring system (IVCM scale)}

An in vivo confocal microscopy (IVCM) scale was used to quantify the ocular surface damage. ${ }^{31}$ The IVCM grading system was developed by Pauly et al. ${ }^{31}$ The system assigned numerical values by degree of severity according to the presence, the cell morphology and nuclear aspects (shape

Table 1. Specificities of the Artificial Tears Used in This Study

\begin{tabular}{|c|c|c|c|c|}
\hline Eye drops & Systane balance & Optive & Vismed & Cationorm \\
\hline Description & $\begin{array}{l}\text { Anionic o/w nanoemulsion } \\
(0.6 \% \text { propylene glycol })\end{array}$ & $\begin{array}{l}0.5 \% \text { CMC; } 0.9 \% \\
\text { glycerin solution }\end{array}$ & $0.18 \%$ HA solution & $\begin{array}{c}\text { Cationic o/w nanoemulsion } \\
(1 \% \text { mineral oil })\end{array}$ \\
\hline Aspect & $\begin{array}{l}\text { White emulsion, } \\
\text { Tyndall effect }\end{array}$ & Colorless solution & Colorless solution & $\begin{array}{c}\text { White emulsion, } \\
\text { Tyndall effect }\end{array}$ \\
\hline $\mathrm{pH}$ & 7.0 & 7.2 & 7.2 & 7.1 \\
\hline $\begin{array}{l}\text { Osmolarity, } \\
\mathrm{mOsm} / \mathrm{kg}\end{array}$ & 277 & 331 & 154 & 194 \\
\hline $\begin{array}{l}\text { Conductivity, } \\
\mathrm{mS} / \mathrm{cm}\end{array}$ & 1.8 & 4.9 & 9.0 & 0.45 \\
\hline Particle size, $\mathrm{nm}$ & 220 & NA & NA & 183 \\
\hline Zeta potential, $\mathrm{mV}$ & -48.4 & NA & -38.6 & +27.4 \\
\hline Viscosity, $\mathrm{mPa} / \mathrm{s}$ & 1.0 & 1.0 & 1.0 & 1.1 \\
\hline $\begin{array}{l}\text { Surface tension, } \\
\mathrm{mN} / \mathrm{m}\end{array}$ & 45.3 & 68.4 & 65.5 & 40.1 \\
\hline Preservative & Polyquaternium-1 (0.001\%) & Purite $^{\circledR}(0.01 \%)$ & Preservative-free & Preservative-free \\
\hline
\end{tabular}

HA, hyaluronic acid. 
and size, reflective pattern), inflammation, and neovascularization. These parameters were scored on basal epithelium, stroma, and endothelium. The individual scores were added to obtain the total HRT score. The maximum score was 55 (28 for epithelium, 14 for endothelium, and 13 for stroma). Scores were obtained for the 5 zones and the average of the 5 zones was calculated for each animal. The number of infiltrating inflammatory cells (lymphocytes, polymorphonuclear cells, or dendritic-like cells) was assessed using the Cell Count ${ }^{\circledR}$ program (Heidelberg Engineering $\mathrm{GmbH}$ ) associated with the HRT II/RCM.

\section{MUC5AC $C^{+}$goblet cells in conjunctiva}

Eyeballs with eyelids were embedded in OCT compound (Tissue-Tek; Sakura Finetek USA, Inc.) and frozen in isopentane cooled in liquid nitrogen. The immunostaining procedure was performed with $6-\mu \mathrm{m}$ frozen nasal, central, and temporal sagittal sections fixed in acetone $\left(-20^{\circ} \mathrm{C}, 10 \mathrm{~min}\right)$. Slides were then incubated with $2 \%$ bovine serum albumin (BSA) to block nonspecific binding. MUC5 $\mathrm{AC}^{+}$goblet cells were analyzed with specific antibody against MUC5AC (1:200 dilution; monoclonal mouse anti-human antibody, ab3649; AbCam). The secondary antibody used was donkey anti-mouse immunoglobulin G labeled with Alexa Fluor 594 (1:500 dilution; Invitrogen). Controls were performed by incubating slides with nonimmune serum in PBS 2\% BSA replacing primary antisera or with PBS replacing conjugated antibodies. For each sample, the extent of immunohistochemical reactivity was evaluated by the number of cells positive for MUC5AC expression per millimeter of epithelium. Tarsal, fornix, and bulbar conjunctiva were considered in the superior and inferior parts of the eyeball. Cells were counted manually using ImageJ software and the Cell Counter plugin (National Institutes of Health).

\section{In vitro stimulation in the HCE-2 cell line}

HCE-2 cells (ATCC) were cultured in KBM-Gold supplemented hormonal epithelial medium and were incubated at $37^{\circ} \mathrm{C}$ under $95 \%$ humidity and $5 \% \mathrm{CO}_{2}$. The cells were seeded in fibronectin/gelatin-coated 96-well plates and cultured in culture medium for $24 \mathrm{~h}$. The medium was then replaced by culture medium containing the test items at a $1 / 10$ dilution and IKK inhibitor $\mathrm{X}(10 \mu \mathrm{M}$, as the internal control of the test) and the cells were incubated for $30 \mathrm{~min}$. After this 30-min incubation period, the medium was changed to fresh medium containing lipopolysaccharide (LPS, $1 \mu \mathrm{g} / \mathrm{mL}$ ) without the test items, and the cells were cultured for another $24 \mathrm{~h}$, after which the culture medium supernatants were collected to quantify IL6 and IL8 release by ELISA (Duo set IL6 and Duo set IL8; R\&D Systems). A viability assay was also performed at the end of the experiment on the cell monolayers according to standard MTT assay procedures.

\section{Statistical analysis}

For the in vivo experiment, no power calculation was done since this was an exploratory experiment. Only a descriptive statistical analysis was performed and the results are presented as the mean \pm standard deviation (SD). For the in vitro experiment, IL6 and IL8 secretion assays were performed in triplicate. The results are presented are the mean of $3 \mathrm{ex}$ periments. A 1-way ANOVA was used to compare variance between groups, and a $t$-test with Bonferroni correction was performed to compare each treatment group with the PBStreated group. Differences were considered significant at $P<0.05$.

\section{Results}

\section{Corneal wound healing following mechanical debridement}

A mechanical corneal superficial epithelium debridement was performed in rats to evaluate the effect of various AT treatments on the recovery process of an altered epithelium. Approximately $50 \%$ of the corneal surface of the right eye of each rat was mechanically scraped, and fluorescein staining was used to quantitate the extent of the corneal alterations (Fig. 1A). As evidenced by fluorescein staining, the corneal wound healing process was complete at day 5; no staining was visible in any treatment group. Figure 1B is a representative picture of a debrided cornea at day 5. At the macroscopic level, neither scarring nor opacities were observed in the debrided corneas treated with the different ATs.

IVCM was used to provide better insight into the corneal changes that may have occurred in the different layers of the tissue (ie, superficial epithelium, basal epithelium, anterior stroma, and endothelium). Following corneal scraping and
A

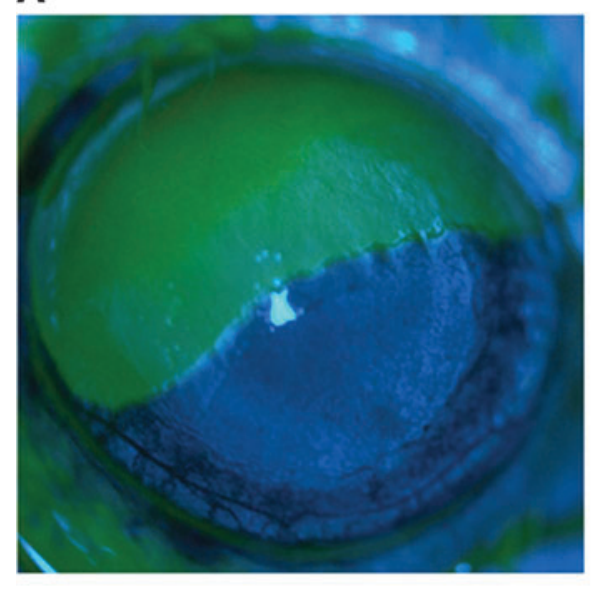

B

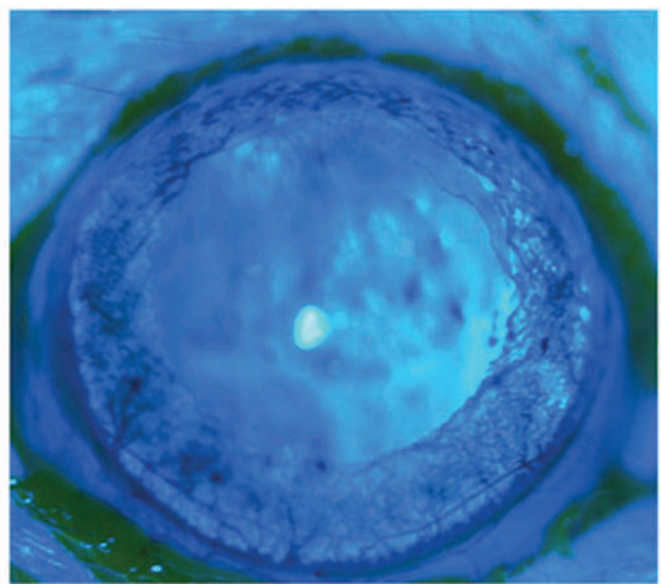

FIG. 1. Corneal fluorescein staining was performed immediately after the scraping of the upper part of the corneal epithelium (on day 1) to characterize the scraped region (A) or at day 5 (B) to evaluate corneal recovery and healing. 
5 days of treatment with the different eye drops (BID), the tissue alterations were scored according to the scale established by Pauly et al. ${ }^{31,32}$ and Liang et al. ${ }^{33}$ (Fig. 2B). Interestingly, the treatment means that were below the grand mean (3.5, overall average of the data without the normal control group) were obtained with the 2 preservative-free AT preparations: Vismed $(2.8 \pm 1.3)$ and Cationorm (2.5 \pm 2.1$)$. In contrast, the soft-preserved AT displayed higher IVCM scores, ranging from 3.5 to 4.3 , with the $0.02 \%$ BAK solution having the highest score: $4.3 \pm 2.9$. Representative IVCM pictures are presented in Fig. 2A.

\section{Inflammatory cell count in the stroma following corneal debridement}

The density of inflammatory cells per square millimeter $\left(\mathrm{mm}^{2}\right)$ was determined with the in vivo confocal microscope in 5 different regions of the stroma. Two of these regions were located exactly under the debrided area of the corneal epithelium, another 2 were located under the intact region of the corneal epithelium, while the fifth one was situated exactly at the interface between the debrided and the intact region of the corneal epithelium. The mean inflammatory cell count at day 5, following twice daily instillations of the different ATs is presented in Fig. 2C. The treatment means that were below the grand mean (17.45, overall average of the data without the normal control group) were obtained with the 2 preservative-free AT preparations: Vismed (13.2 \pm 12.3$)$ and Cationorm (7.3 \pm 6.5$)$. In contrast, the number of inflammatory cells following corneal debridement and twice daily instillations in the soft-preserved AT-treated groups ranged from 18 to 30 cells $/ \mathrm{mm}^{2}$. Surprisingly, the soft preservation systems, Purite ${ }^{\circledR}$ and Polyquad ${ }^{\circledR}$, did not perform better than a $0.02 \%$ BAK solution instilled twice daily. Both quaternary ammonium-containing preparations presented a similar inflammatory cell density in the stroma, $17.8 \pm 15.5$ and $21.4 \pm 11.2$ cells $/ \mathrm{mm}^{2}$, for the $0.02 \%$ BAK solution and Systane Balance, respectively.

\section{In vitro characterization of the anti-inflammatory properties of the ATs following LPS challenge}

The anti-inflammatory properties of the different ATs were evaluated in HCE-2 cells with a protocol designed to

\section{A Basal
epithelium}

\section{Anterior stroma}

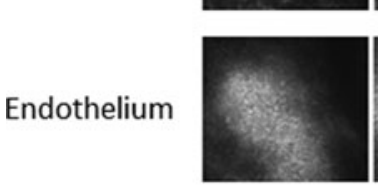
Control

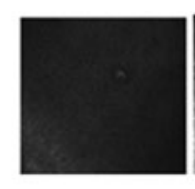

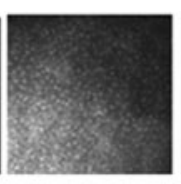
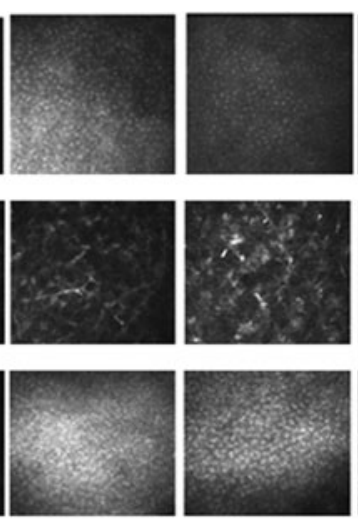

PBS
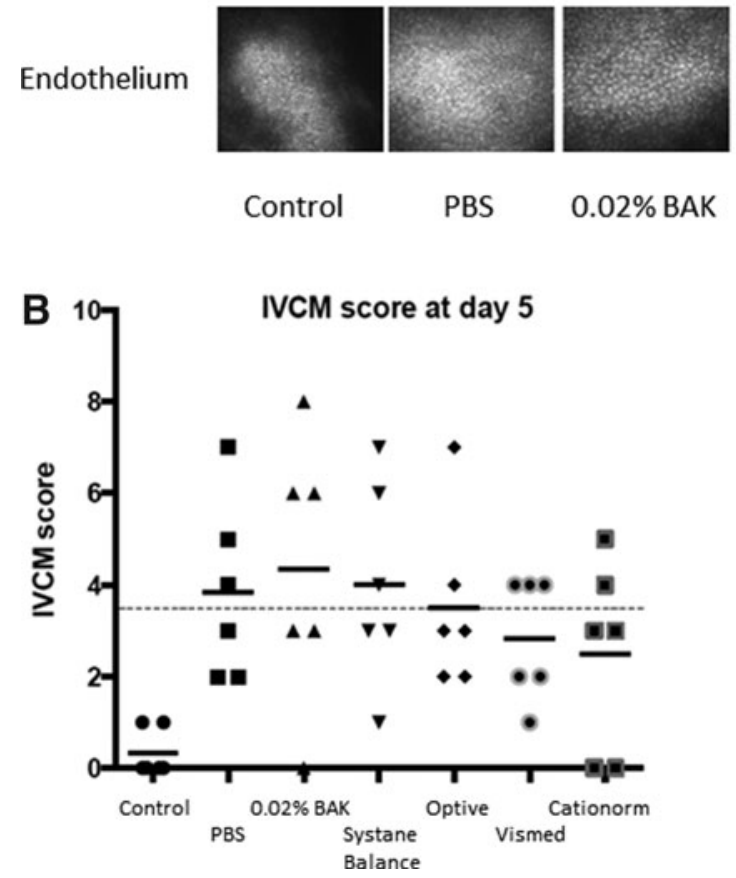
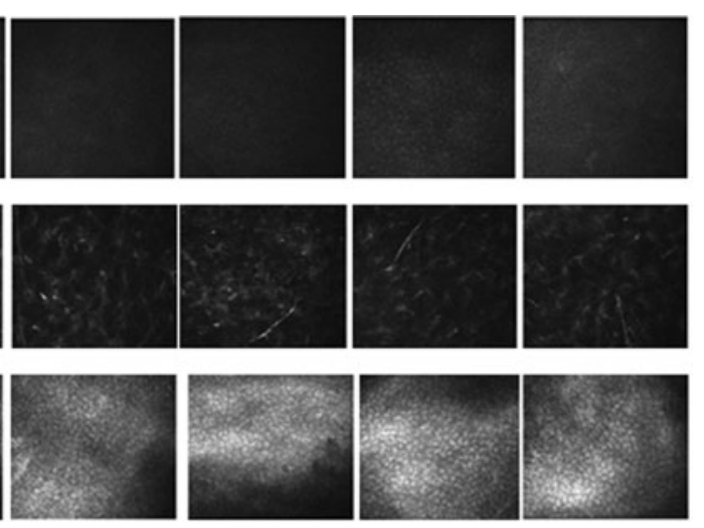

Systane

Optive

Vismed

Cationorm

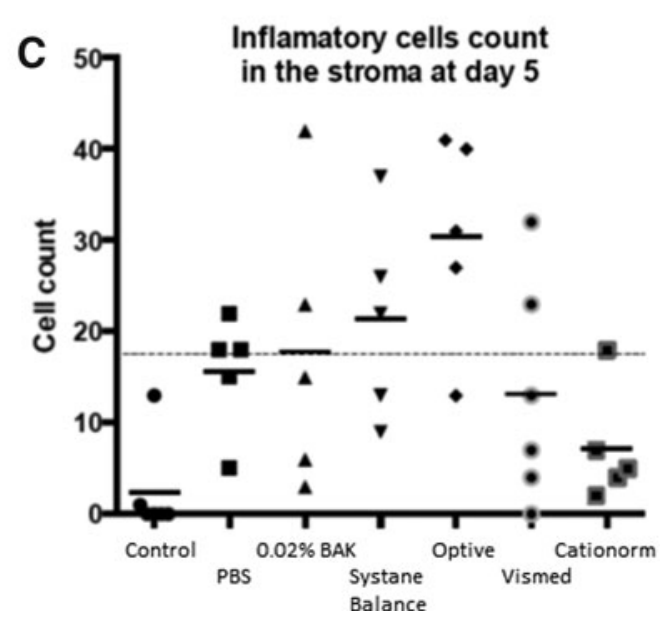

FIG. 2. In vivo confocal microscopy (IVCM) characterization of the cornea at day 5 following corneal scraping and 5 days of treatment with the different eye drop preparations. (A) Representative pictures of the corneal epithelium, stroma, and endothelium. (B) Tissue alterations scored according to Pauly et al. ${ }^{31}$ IVCM scale. (C) Corneal inflammation was characterized by assessing the density of infiltrated inflammatory cells within the stroma. The unpreserved eye drop preparations show a trend toward a lower inflammation scatterplot of the data. The plot includes the grand mean of the data as a dotted line (normal control group excluded) and the individual treatment means as a solid line. 

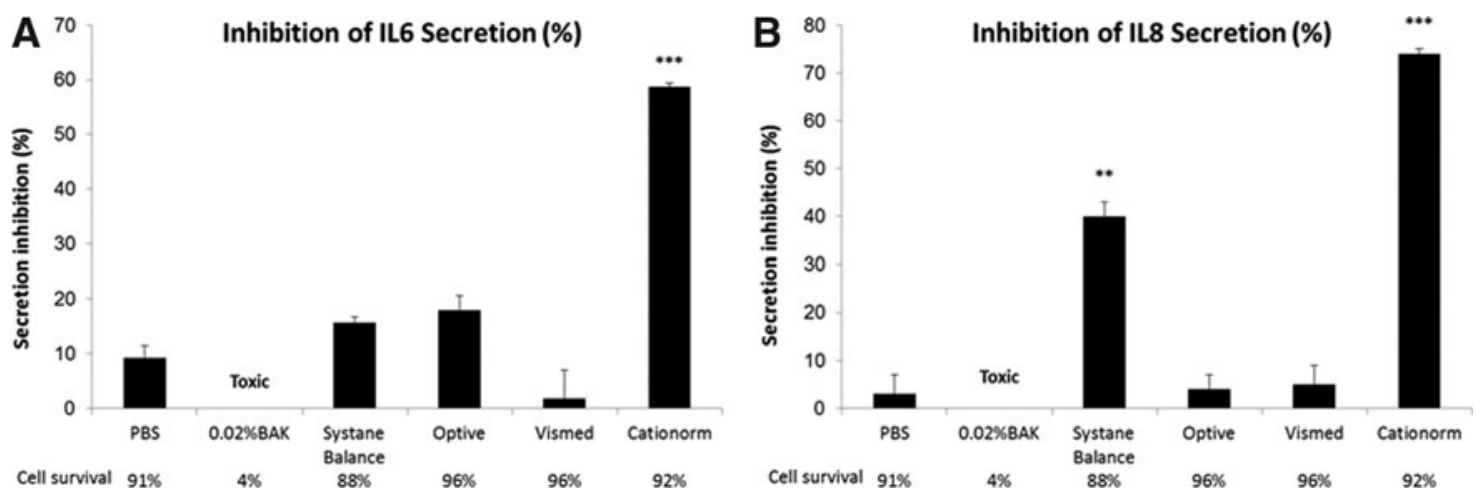

FIG. 3. In vitro anti-inflammatory properties in HCE-2 cells following lipopolysaccharide stimulation and treatment with the different artificial tears (ATs). (A) IL6 and (B) IL8 secretion inhibition. $* * P<0.01$; $* * * P<0.001$ versus phosphatebuffered saline (PBS).

mimic the residence time and the dilution by tears observed for any instilled eye drops. A subconfluent HCE-2 cell monolayer stimulated with LPS was incubated for $30 \mathrm{~min}$ in the presence of $1 / 10$ dilutions of the different ATs. After $30 \mathrm{~min}$, the cell culture medium containing the diluted AT was replaced by fresh medium containing LPS and the cells were cultured for another $24 \mathrm{~h}$. This medium was then collected to quantitate the amounts of IL6 and IL8 secreted during the 24-h incubation period (Fig. 3). An MTT cell viability test performed on the cells at the end of the 24-h incubation period confirmed that the $10 \%$ dilution of the $0.02 \%$ BAK solution was toxic: $4 \%$ cell survival was observed following the 30 -min treatment with the $0.02 \%$ BAK solution, hence no reliable IL6 and IL8 secretion could be calculated for the $0.02 \%$ BAK solution. In contrast, all the commercial ATs were very well tolerated, with cell survival values ranging from $88 \%$ to $96 \%$. IKK inhibitor $\mathrm{X}$ was very effective at inhibiting the secretion of both IL6 (74\% inhi-

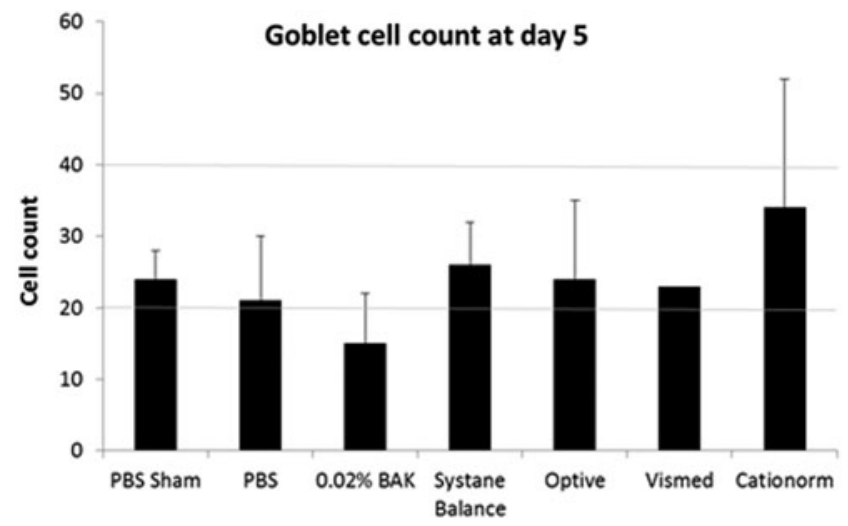

FIG. 4. Following corneal scraping and 5 days of treatment with the different eye drop preparations, mucinpositive goblet cell density was assessed within the ocular surface; $0.02 \%$ BAK instillations resulted in a decrease in mucin-positive goblet cells, while the ATs were all able to maintain the density of mucin-positive goblet cells, with Cationorm ${ }^{\circledR}$ being the only one to present a trend toward an increase in mucin-positive goblet cell density. bition) and IL8 (72\% inhibition), thus confirming the validity of the assay (data not shown).

Effects on IL6 secretion. Cationorm reduced the secretion of IL6 by $59 \%$, while the other 3 ATs displayed secretion inhibition levels that were within the range of the level observed for PBS (9\%) (Fig. 3A). Even though the inhibition values observed for Systane Balance (16\%) and Optive (18\%) were higher than the value observed for PBS, no statistically significant difference was reached for either AT.

Effects on IL8 secretion. Cationorm reduced the secretion of IL8 by $74 \%$ and Systane Balance by $40 \%$. Vismed, Optive, and PBS did not have any significant effect on IL8 secretion (Fig. 3B). They inhibited the secretion of IL8 only by $5 \%, 4 \%$, and $3 \%$, respectively.

\section{Goblet cell count in the conjunctiva of scraped cornea eyes}

The number of mucin-positive goblet cells was determined in the bulbar conjunctiva and fornix, and the mean density of mucin-positive goblet cells per field is presented in Fig. 4. In the control group, the negative control PBS-treated rat, the density of mucin-positive goblet cells was $24 \pm 4$ cells/field. Interestingly, only in the $0.02 \%$ BAK solution-treated group did the density of mucin-positive goblet cells decrease to $15 \pm 7$ cells/ field. In contrast, this density was maintained at values close (range 23-26 cells/field) to the density observed for the control group for Systane Balance, Optive, and Vismed. On the other hand, only the eyes treated with the cationic emulsion (Cationorm) for 5 days presented a trend toward an increase in the density of mucin-positive goblet cells ( $34 \pm 18$ cells/field).

\section{Discussion}

DED is a complex multifactorial disease of the TF and ocular surface, ${ }^{3}$ in which inflammation is an important player. ${ }^{8}$ Inflammation can simultaneously be both a triggering and an exacerbating factor of the disease. ${ }^{9,10,34}$ Cyclosporin and steroids are the main classes of anti-inflammatory compounds found in prescription medicines routinely used for the treatment of signs and/or symptoms of dry eye. ${ }^{35-37}$ Cyclosporin, as compounded hospital preparations or Restasis ${ }^{\circledR}(0.05 \%$ 
CsA; Allergan), has been used for more than 20 years in many European countries and since 2003 in the United States. While corticosteroids, such as methylprednisolone, loteprednol etabonate, and fluorometholone, are effective anti-inflammatory therapies in DED, ${ }^{36,38,39}$ their side effects ${ }^{36}$ limit their use to short periods of time. However, these compounds are not the first-line therapy for the management of patients with mild to moderate DED, a position held by ATs, even though active inflammation is also likely to be present in these patients with less severe DED.

ATs are mainly ocular lubricants specifically formulated to moisten the eyes and restore a well-hydrated ocular surface environment that helps protect the corneal epithelium through mechanical action. There are many different brands $(>300 \text {; www.goodguide.com) })^{40}$ and forms (aqueous solutions, emulsions, ointments) of ATs ${ }^{41,42}$ on the market. They are used for temporary relief of the burning and irritation sensations and the discomfort caused by DED. Due to their low side effect profile, they are the first-line therapy in the management of symptoms and signs of DED. ${ }^{1-13}$ HA, carboxymethyl cellulose, polyols such as glycerol or mannitol, and oils are the active ingredients often found in ATs and are the compounds responsible for their beneficial (mechanical) action on the ocular surface. ${ }^{43,44}$

The present study compared the wound healing and the net anti-inflammatory properties of ATs using different strategies to moisturize and protect the ocular surface. In the rat, superficial corneal debridement wounds reepithelialize rapidly ${ }^{4,46}$ and do not induce differentiation or morphological changes in the superficial corneal epithelium. Hence, superficial corneal abrasions, that is, lesions located in the epithelium and not reaching the stroma, were used as the proinflammatory stress to evaluate the efficacy of ATs. Indeed, animal models of corneal injury reveal an acute inflammatory response. Within hours after wounding, the resident leukocytes become activated and recruit other leukocytes from the limbus into the stroma. ${ }^{47,48}$

This study shows that the wound healing pace of these superficial abrasions was not modified by the twice daily applications of ATs. Five days after corneal debridement, the clinical observations (corneal fluorescein staining, Fig. 1B) confirmed the complete reepithelialization of the cornea, whatever the AT used. Surprisingly, twice daily instillations of the $0.02 \%$ BAK solution were also quite well tolerated in this animal model.

Since the corneal debridement was performed in healthy rats with no underlying systemic or ocular diseases or inflammation, it is possible that the 5-day time frame of the experiment was too short for repeated instillations of $0.02 \%$ BAK solution to induce deleterious effects. In patients, deleterious effects of repeated instillations of BAKcontaining eye drops become evident after a relatively long period of use $\mathrm{e}^{49}$ and are predominantly seen in patients already presenting ocular surface alterations or subclinical levels of inflammation, such as in DED, glaucoma, or diabetic patients. 50

The relatively low values of the IVCM score presented in Fig. 2B also indicate that the corneal epithelium healed quite well. However, it is interesting to note that there is a trend toward lower scores with the preservative-free ATsVismed and Cationorm-and the lower the score, the better. It is also worth mentioning that these 2 ATs are also hypoosmotic (Table 1), and it cannot be excluded that the low osmolarity might have beneficial effects as well. Altogether, these data suggest that an endpoint at day 5 following a superficial corneal abrasion does not allow us to discriminate the different ATs even if corneal epithelium debridement that leaves the basement membrane intact is an ideal model for quantifying reepithelialization or cell proliferation rates. $^{30}$

A minimal rehydration (with PBS) of the ocular surface in healthy rats seems to be sufficient for the restoration of the corneal epithelium.

This study also demonstrates that the ATs tested are well tolerated as they do not alter the healing process. This is confirmed by the evaluation of the number of goblet cells present at the end of the experiment, which for the 4 ATs remains similar to the level observed in the PBS sham group. In contrast, animals treated with the $0.02 \% \mathrm{BAK}$ solution had their goblet cell count decreased by $37.5 \%$, probably as an early indication of BAK toxicity. It is well known that repeated instillation of BAK-preserved eye drops reduces the number of goblet cells present on the ocular surface. ${ }^{49,51}$ An elevated goblet cell count is therefore an indication of the good tolerance of the 4 ATs.

It is particularly worth noting that in the Cationormtreated animals, there was a trend toward an increase in the goblet cell count (close to a $40 \%$ increase in the goblet cell count per field, Fig. 4). ${ }^{33}$ Due to the relatively low number of animals per group, this difference did not reach statistical significance. However, this is an argument that Cationorm, in addition to its good tolerance, may also possess advantageous properties that help protect the ocular surface. ${ }^{33}$

In these corneas with a healed superficial epithelium, inflammation was expected to be relatively low with inflammatory cell counts in the stroma for the 4 ATs close to the value observed in the PBS sham group ( $2.3 \pm 5.1$ cells $/ \mathrm{mm}^{2} ;$ Fig. $\left.2 \mathrm{C}\right)$, even though the exact kinetics of the different rounds of inflammatory cell recruitment after corneal debridement is not well known. ${ }^{48,52}$ However, the 2 soft-preserved ATs, Systane Balance and Optive, displayed inflammatory cell counts higher than the PBS sham group $\left(\sim 20-30\right.$ cells $\left./ \mathrm{mm}^{2}\right)$, whereas for Vismed and Cationorm, that is, the 2 preservative-free ATs, the cell counts were not significantly different from the PBS sham.

These data suggest that an underlying inflammation may still be present in corneas with healed superficial epithelium when treated with the soft-preserved ATs, while this inflammation is reduced with the 2 preservative-free ATs. At this stage, it is not clear whether this inflammation at day 5 stems from the inflammation induced by the abrasion procedure or if the repeated instillations of the soft-preserved ATs may also negatively contribute to the inflammation observed in the stroma. It is well known that hyperosmolar tears are proinflammatory, ${ }^{7,53,54}$ and Optive with an osmolarity of $331 \mathrm{mOsm} / \mathrm{kg}$ (Table 1) also displayed the highest inflammatory cell count in the corneal stroma (Fig. 2C).

If we consider that the twice daily PBS instillations have no direct effect on inflammation, then the inflammatory cell count observed in the PBS-treated group could represent the inflammation that was induced by the corneal abrasion procedure that is slowly tapered down following the completion of the healing process within the superficial epithelium. Indeed, numerous epithelial abrasion studies have documented the presence of neutrophils within the corneal stroma as early as $6 \mathrm{~h}$ after injury. ${ }^{48,52,55,56}$ These neutrophils transmigrate from the limbal vessels and through the 
stroma into the injured area. ${ }^{57}$ The number of neutrophils in the injured cornea peaks $24-48 \mathrm{~h}$ after injury before decreasing, while other cell types, such as macrophages, begin to appear. Macrophages, in concert with neutrophils, phagocytose cellular debris. They are the source of chemoattractants and growth factors that promote the resolution of inflammation, epithelial cell migration, and proliferation for wound closure and healing.

The 4 ATs can be separated into 2 groups: (i) the preservative-free and hypo-osmolar ATs (Cationorm and Vismed), with a mean inflammatory cell count lower than the PBS group, and (ii) the soft-preserved ATs (Systane Balance, iso-osmolar, Optive, hyper-osmolar), with an inflammatory cell count higher than the PBS group. This difference in inflammation could be related to the presence or absence of a preservative agent or to the higher osmolarity found in these ATs. Several animal studies have demonstrated that exposure to BAK-containing eye drops results in overexpression of inflammatory markers, such as HLA-DR, ICAM-1, or Fas ${ }^{58}$ together with a conjunctival infiltration of inflammatory cells. ${ }^{59}$ By contrast, Polyquad is described as being well tolerated in animal models ${ }^{60,61}$ and in vitro, ${ }^{62}$ while the stabilized oxychloro complex (Purite) was shown to have some toxicity in vitro. ${ }^{63}$

To further explore and confirm the anti-inflammatory trend seen in vivo (Fig. 2C), an in vitro test in HCE-2 cells was used to characterize the ability of the 4 ATs to inhibit IL8 and IL6 secretion following LPS stimulation (Fig. 3). IL8 was chosen because it is a chemotactic agent implicated in the recruitment of inflammatory cells and IL6 because it is an acute-phase proinflammatory cytokine. The test was designed to mimic the residence time and the dilution of the ATs that occur following their applications onto the eye. ${ }^{33}$ While Vismed and Cationorm presented a low level of inflammatory cells in the corneal stroma, only Cationorm effectively inhibited the secretion of both IL8 and IL6, suggesting that this cationic emulsion, in addition to its good in vitro tolerance, ${ }^{64}$ also possesses a direct effect on some of the proinflammatory markers found in diseased corneas.

In contrast, no such effects were observed for Vismed in this experimental setting; however, HA (Vismed) has been described to possess some anti-inflammatory properties. ${ }^{17,65,66}$ High-molecular-weight HA (HMW-HA >10 Da) has been described to be anti-inflammatory, ${ }_{5}^{67}$ while low-molecular-weight HA (LMW-HA: $2-5 \times 10^{5}$ Da) is proinflammatory through mainly TLR2 and TLR4 activation. However, HMW-HA can be degraded in LMW-HA by reactive oxygen species generated during inflammation. ${ }^{68,69}$ This reduced and better inflammatory cell count observed in vivo following Vismed treatment when compared with Systane Balance or Optive might also be the result of a hypo-osmolarity-induced osmoprotection. ${ }^{7,70}$

In vitro, Systane Balance was able to modulate the secretion of IL8. However, this moderate in vitro antiinflammatory action was not seen in vivo following the twice daily instillations over the 5-day period. The presence of the soft preservative agent, Polyquaternium-1, in Systane Balance and the repeated instillation dosing regimen might be the reason for the in vitro effect not transferring to the in vivo experiment. Even though both ATs are generally well tolerated in patients, the prolonged use of these ATs and the presence of the soft preservative agents on the ocular surface might maintain a low subclinical level of chronic inflammation within the cornea. The underlying corneal inflammation that might be present following soft-preserved or hyper-osmolar AT treatments can be the cause for the loss of efficacy often seen in long-term AT treatments.

In this study, we have demonstrated that repeated instillations of both soft-preserved (Systane Balance and Optive) and preservative-free ATs (Vismed and Cationorm) are well tolerated by diseased eyes presenting superficial corneal epithelial abrasions. The different AT treatments have only a minor impact on the wound healing pace as corneal healing was complete within 5 days.

However, preservative-free Cationorm and Vismed presented lower residual inflammation within the stroma of the treated eyes at the end of the treatment period when compared with the soft-preserved Systane Balance or Optive.

While Vismed's inflammatory cell count in the stroma may be explained by HA (depending on its HA molecular weight), the absence of any soft preservative agent, or its hypo-osmolarity, only the preservative-free AT Cationorm seems to harbor direct anti-inflammatory properties. This anti-inflammatory effect is probably not solely related to a mechanical improvement of the ocular surface environment brought by the AT since in that case the same reduced inflammatory cell count would have been seen for each of the 4 ATs.

Cationorm is a hypo-osmolar cationic oil-in-water emulsion, in which the positive charges of the oil nanodroplets are brought by CKC, a quaternary ammonium with a lipophilic 16-carbon aliphatic chain. The electrostatic interactions between the positively charged oil nanodroplets and the negatively charged ocular surface are responsible for the rapid spreading and improved residence time of the cationic emulsion on the ocular surface. ${ }^{25}$ The low dose and the high lipophilicity of the cationic agent (CKC) also prevent ocular toxicity of the cationic emulsion, even though the cationic agent is a quaternary ammonium. ${ }^{25}$ Repeated instillations of Cationorm were demonstrated to be safe and well tolerated in animal models: in an acute toxicity rabbit model (up to 15 instillations over $75 \mathrm{~min})^{71}$ and in 28-day local tolerance studies in the rabbit (6 instillations per day for 28 days), as well as in patients. ${ }^{26,27}$ These good safety and efficacy profiles clearly position Cationorm as a promising new AT for the management of signs and symptoms of dry eye in mild to moderate DED patients presenting chronic subclinical levels of ocular inflammation.

\section{Author Disclosure Statement}

P.D. and J.-S.G. are Santen SAS employees; L.F. and P.-P.E. are Iris Pharma employees.

\section{References}

1. Schein, O.D., Tielsch, J.M., Munoz, B., Bandeen-Roche, K., and West, S. Relation between signs and symptoms of dry eye in the elderly. A population-based perspective. Ophthalmology. 104:1395-1401, 1997.

2. Moss, S.E., Klein, R., and Klein, B.E. Incidence of dry eye in an older population. Arch. Ophthalmol. 122:369-373, 2004.

3. Lemp, M., Baudouin, C., Baum, J., Dogru, M., Foulks, G.N., Kinoshita, S., Laibson, P., McCulley, J., Murube, J., 
Pflugfelder, S., Rolando, M., and Toda, I. The definition and classification of dry eye disease: report of the Definition and Classification Subcommittee of the International Dry Eye WorkShop (2007). Ocul. Surf. 5:75-92, 2007.

4. Viso, E., Rodriguez-Ares, M.T., and Gude, F. Prevalence of and associated factors for dry eye in a Spanish adult population (the Salnes Eye Study). Ophthalmic Epidemiol. 16:15-21, 2009.

5. Paulsen, A.J., Cruickshanks, K.J., Fischer, M.E., Huang, G.H., Klein, B.E., Klein, R., and Dalton, D.S. Dry eye in the Beaver Dam Offspring Study: prevalence, risk factors, and health-related quality of life. Am. J. Ophthalmol. 157:799-806, 2014.

6. Baudouin, C. A new approach for better comprehension of diseases of the ocular surface. J. Fr. Ophtalmol. 30:239246, 2007.

7. Baudouin, C., Aragona, P., Messmer, E.M., Tomlinson, A., Calonge, M., Boboridis, K.G., Akova, Y.A., Geerling, G., Labetoulle, M., and Rolando, M. Role of hyperosmolarity in the pathogenesis and management of dry eye disease: proceedings of the OCEAN group meeting. Ocul. Surf. 11:246-258, 2013.

8. Wei, Y., and Asbell, P.A. The core mechanism of dry eye disease is inflammation. Eye Contact Lens. 40:248-256, 2014.

9. De Paiva, C.S., and Pflugfelder, S.C. Rationale for antiinflammatory therapy in dry eye syndrome. Arq. Bras. Oftalmol. 71:89-95, 2008.

10. Calonge, M., Enriquez-de-Salamanca, A., Diebold, Y., Gonzalez-Garcia, M.J., Reinoso, R., Herreras, J.M., and Corell, A. Dry eye disease as an inflammatory disorder. Ocul. Immunol. Inflamm. 18:244-253, 2010.

11. Williamson, J.F., Huynh, K., Weaver, M.A., and Davis, R.M. Perceptions of dry eye disease management in current clinical practice. Eye Contact Lens. 40:111-115, 2014.

12. O'Brien, P.D., and Collum, L.M. Dry eye: diagnosis and current treatment strategies. Curr. Allergy Asthma Rep. 4:314319, 2004.

13. Sindt, C.W., and Foulks, G.N. Efficacy of an artificial tear emulsion in patients with dry eye associated with meibomian gland dysfunction. Clin. Ophthalmol. 7:1713-1722, 2013.

14. Khanal, S., Tomlinson, A., Pearce, E.I., and Simmons, P.A. Effect of an oil-in-water emulsion on the tear physiology of patients with mild to moderate dry eye. Cornea. 26:175181, 2007.

15. Uchiyama, E., Di Pascuale, M.A., Butovich, I.A., and McCulley, J.P. Impact on ocular surface evaporation of an artificial tear solution containing hydroxypropyl guar. Eye Contact Lens. 34:331-334, 2008.

16. McCann, L.C., Tomlinson, A., Pearce, E.I., and Papa, V. Effectiveness of artificial tears in the management of evaporative dry eye. Cornea. 31:1-5, 2012.

17. Brignole, F., Pisella, P.J., Dupas, B., Baeyens, V., and Baudouin, C. Efficacy and safety of $0.18 \%$ sodium hyaluronate in patients with moderate dry eye syndrome and superficial keratitis. Graefes Arch. Clin. Exp. Ophthalmol. 243:531-538, 2005.

18. Vogel, R., Crockett, R.S., Oden, N., Laliberte, T.W., Molina, L., and Sodium Hyaluronate Ophthalmic Solution Study Group. Demonstration of efficacy in the treatment of dry eye disease with $0.18 \%$ sodium hyaluronate ophthalmic solution (vismed, rejena). Am. J. Ophthalmol. 149:594-601, 2010.

19. Chen, W., Zhang, X., Liu, M., Zhang, J., Ye, Y., Lin, Y., Luyckx, J., and Qu, J. Trehalose protects against ocular surface disorders in experimental murine dry eye through suppression of apoptosis. Exp. Eye Res. 89:311-318, 2009.

20. Cejkova, J., Ardan, T., Cejka, C., and Luyckx, J. Favorable effects of trehalose on the development of UVB-mediated antioxidant/pro-oxidant imbalance in the corneal epithelium, proinflammatory cytokine and matrix metalloproteinase induction, and heat shock protein 70 expression. Graefes Arch. Clin. Exp. Ophthalmol. 249:1185-1194, 2011.

21. Li, J., Roubeix, C., Wang, Y., Shi, S., Liu, G., Baudouin, C., and Chen, W. Therapeutic efficacy of trehalose eye drops for treatment of murine dry eye induced by an intelligently controlled environmental system. Mol. Vis. 18:317-329, 2012.

22. Rashid, S., Jin, Y., Ecoiffier, T., Barabino, S., Schaumberg, D.A., and Dana, M.R. Topical omega-3 and omega-6 fatty acids for treatment of dry eye. Arch. Ophthalmol. 126:219225, 2008.

23. Li, Z., Choi, J.H., Oh, H.J., Park, S.H., Lee, J.B., and Yoon, K.C. Effects of eye drops containing a mixture of omega-3 essential fatty acids and hyaluronic acid on the ocular surface in desiccating stress-induced murine dry eye. Curr. Eye Res. 39:871-878, 2014.

24. Lallemand, F., Daull, P., Benita, S., Buggage, R., and Garrigue, J.S. Successfully improving ocular drug delivery using the cationic nanoemulsion Novasorb. J. Drug Deliv. 2012:604204, 2012.

25. Daull, P., Lallemand, F., and Garrigue, J.S. Benefits of cetalkonium chloride cationic oil-in-water nanoemulsions for topical ophthalmic drug delivery. J. Pharm. Pharmacol. 66:531-541, 2014.

26. Amrane, M., Creuzot-Garcher, C., Robert, P.Y., Ismail, D., Garrigue, J.S., Pisella, P.J., and Baudouin, C. Ocular tolerability and efficacy of a cationic emulsion in patients with mild to moderate dry eye disease - a randomised comparative study. J. Fr. Ophtalmol. 37:589-598, 2014.

27. Ismail, D., Amrane, M., Robert, P.-Y., and Baudouin, C. Efficacy of Cationorm ${ }^{\circledR}$ Preservative-Free Cationic Emulsion Versus Vismed ${ }^{\circledR}(0.18 \%$ Hyaluronic Acid) in Moderate to Severe Dry Eye Disease (DED) Patients. Reykjavik: ISOPT; 2014.

28. Murakami, J., Nishida, T., and Otori, T. Coordinated appearance of beta 1 integrins and fibronectin during corneal wound healing. J. Lab. Clin. Med. 120:86-93, 1992.

29. Stepp, M.A., Spurr-Michaud, S., and Gipson, I.K. Integrins in the wounded and unwounded stratified squamous epithelium of the cornea. Invest. Ophthalmol. Vis. Sci. 34:18291844, 1993.

30. Stepp, M.A., Zieske, J.D., Trinkaus-Randall, V., Kyne, B.M., Pal-Ghosh, S., Tadvalkar, G., and Pajoohesh-Ganji, A. Wounding the cornea to learn how it heals. Exp. Eye Res. 121:178-193, 2014.

31. Pauly, A., Labbe, A., Baudouin, C., Liang, H., Warnet, J.M., and Brignole-Baudouin, F. In vivo confocal microscopic grading system for standardized corneal evaluation: application to toxic-induced damage in rat. Curr. Eye Res. 33:826-838, 2008.

32. Pauly, A., Brignole-Baudouin, F., Labbe, A., Liang, H., Warnet, J.M., and Baudouin, C. New tools for the evaluation of toxic ocular surface changes in the rat. Invest. Ophthalmol. Vis. Sci. 48:5473-5483, 2007.

33. Liang, H., Baudouin, C., Daull, P., Garrigue, J.S., and Brignole-Baudouin, F. In vitro and in vivo evaluation of a preservative-free cationic emulsion of latanoprost in corneal wound healing models. Cornea. 31:1319-1329, 2012. 
34. Gumus, K., and Cavanagh, D.H. The role of inflammation and antiinflammation therapies in keratoconjunctivitis sicca. Clin. Ophthalmol. 3:57-67, 2009.

35. Sall, K., Stevenson, O.D., Mundorf, T.K., and Reis, B.L. Two multicenter, randomized studies of the efficacy and safety of cyclosporine ophthalmic emulsion in moderate to severe dry eye disease. CsA Phase 3 Study Group. Ophthalmology. 107:631-639, 2000.

36. Marsh, P., and Pflugfelder, S.C. Topical nonpreserved methylprednisolone therapy for keratoconjunctivitis sicca in Sjogren syndrome. Ophthalmology. 106:811-816, 1999.

37. Byun, Y.J., Kim, T.I., Kwon, S.M., Seo, K.Y., Kim, S.W., Kim, E.K., and Park, W.C. Efficacy of combined $0.05 \%$ cyclosporine and $1 \%$ methylprednisolone treatment for chronic dry eye. Cornea. 31:509-513, 2012.

38. Pflugfelder, S.C. Antiinflammatory therapy for dry eye. Am. J. Ophthalmol. 137:337-342, 2004.

39. Yang, C.Q., Sun, W., and Gu, Y.S. A clinical study of the efficacy of topical corticosteroids on dry eye. J. Zhejiang Univ. Sci. B. 7:675-678, 2006.

40. Goodguide. Available at www.goodguide.com/, accessed July 2015.

41. Alves, M., Fonseca, E.C., Alves, M.F., Malki, L.T., Arruda, G.V., Reinach, P.S., and Rocha, E.M. Dry eye disease treatment: a systematic review of published trials and a critical appraisal of therapeutic strategies. Ocul. Surf. 11:181-192, 2013.

42. Moshirfar, M., Pierson, K., Hanamaikai, K., SantiagoCaban, L., Muthappan, V., and Passi, S.F. Artificial tears potpourri: a literature review. Clin. Ophthalmol. 8:14191433, 2014.

43. Doughty, M.J., and Glavin, S. Efficacy of different dry eye treatments with artificial tears or ocular lubricants: a systematic review. Ophthalmic Physiol. Opt. 29:573-583, 2009.

44. Sanchez, M.A., Torralbo-Jimenez, P., Giron, N., de la Heras, B., Herrero Vanrell, R., Arriola-Villalobos, P., Diaz-Valle, D., Alvarez-Barrientos, A., and Benitez-Del-Castillo, J.M. Comparative analysis of carmellose $0.5 \%$ versus hyaluronate $0.15 \%$ in dry eye: a flow cytometric study. Cornea. 29:167-171, 2010.

45. Chi, C., and Trinkaus-Randall, V. New insights in wound response and repair of epithelium. J. Cell. Physiol. 228: 925-929, 2013.

46. Nagai, N., Murao, T., Okamoto, N., and Ito, Y. Comparison of corneal wound healing rates after instillation of commercially available latanoprost and travoprost in rat debrided corneal epithelium. J. Oleo. Sci. 59:135-141, 2010.

47. Li, Z., Burns, A.R., Miller, S.B., and Smith, C.W. CCL20, gammadelta T cells, and IL-22 in corneal epithelial healing. FASEB J. 25:2659-2668, 2011.

48. Pal-Ghosh, S., Pajoohesh-Ganji, A., Menko, A.S., Oh, H.Y., Tadvalkar, G., Saban, D.R., and Stepp, M.A. Cytokine deposition alters leukocyte morphology and initial recruitment of monocytes and gammadeltaT cells after corneal injury. Invest. Ophthalmol. Vis. Sci. 55:2757-2765, 2014.

49. Baudouin, C., Labbe, A., Liang, H., Pauly, A., and Brignole-Baudouin, F. Preservatives in eyedrops: the good, the bad and the ugly. Prog. Retin. Eye Res. 29:312-334, 2010 .

50. Threatt, J., Williamson, J.F., Huynh, K., and Davis, R.M. Ocular disease, knowledge and technology applications in patients with diabetes. Am. J. Med. Sci. 345:266-270, 2013.
51. Kahook, M.Y., and Noecker, R. Quantitative analysis of conjunctival goblet cells after chronic application of topical drops. Adv. Ther. 25:743-751, 2008.

52. Li, Z., Burns, A.R., and Smith, C.W. Two waves of neutrophil emigration in response to corneal epithelial abrasion: distinct adhesion molecule requirements. Invest. Ophthalmol. Vis. Sci. 47:1947-1955, 2006.

53. Luo, L., Li, D.Q., Corrales, R.M., and Pflugfelder, S.C. Hyperosmolar saline is a proinflammatory stress on the mouse ocular surface. Eye Contact Lens. 31:186-193, 2005.

54. Versura, P., Profazio, V., Schiavi, C., and Campos, E.C. Hyperosmolar stress upregulates HLA-DR expression in human conjunctival epithelium in dry eye patients and in vitro models. Invest. Ophthalmol. Vis. Sci. 52:5488-5496, 2011.

55. Gao, Y., Li, Z., Hassan, N., Mehta, P., Burns, A.R., Tang, X., and Smith, C.W. NK cells are necessary for recovery of corneal CD11c+ dendritic cells after epithelial abrasion injury. J. Leukoc. Biol. 94:343-351, 2013.

56. Byeseda, S.E., Burns, A.R., Dieffenbaugher, S., Rumbaut, R.E., Smith, C.W., and Li, Z. ICAM-1 is necessary for epithelial recruitment of gammadelta $\mathrm{T}$ cells and efficient corneal wound healing. Am. J. Pathol. 175:571-579, 2009.

57. Gagen, D., Laubinger, S., Li, Z., Petrescu, M.S., Brown, E.S., Smith, C.W., and Burns, A.R. ICAM-1 mediates surface contact between neutrophils and keratocytes following corneal epithelial abrasion in the mouse. Exp. Eye Res. 91:676-684, 2010.

58. Baudouin, C., Pisella, P.J., Fillacier, K., Goldschild, M., Becquet, F., De Saint Jean, M., and Bechetoille, A. Ocular surface inflammatory changes induced by topical antiglaucoma drugs: human and animal studies. Ophthalmology. 106:556-563, 1999.

59. Noecker, R.J., Herrygers, L.A., and Anwaruddin, R. Corneal and conjunctival changes caused by commonly used glaucoma medications. Cornea. 23:490-496, 2004.

60. Labbe, A., Pauly, A., Liang, H., Brignole-Baudouin, F., Martin, C., Warnet, J.M., and Baudouin, C. Comparison of toxicological profiles of benzalkonium chloride and polyquaternium-1: an experimental study. J. Ocul. Pharmacol. Ther. 22:267-278, 2006.

61. Liang, H., Brignole-Baudouin, F., Riancho, L., and Baudouin, C. Reduced in vivo ocular surface toxicity with polyquadpreserved travoprost versus benzalkonium-preserved travoprost or latanoprost ophthalmic solutions. Ophthalmic Res. 48:89-101, 2012.

62. Brignole-Baudouin, F., Riancho, L., Liang, H., Nakib, Z., and Baudouin, C. In vitro comparative toxicology of polyquadpreserved and benzalkonium chloride-preserved travoprost/ timolol fixed combination and latanoprost/timolol fixed combination. J. Ocul. Pharmacol. Ther. 27:273-280, 2011.

63. Xu, M., Sivak, J.G., and McCanna, D.J. Comparison of the effects of ophthalmic solutions on human corneal epithelial cells using fluorescent dyes. J. Ocul. Pharmacol. Ther. 29:794-802, 2013.

64. Kinnunen, K., Kauppinen, A., Piippo, N., Koistinen, A., Toropainen, E., and Kaarniranta, K. Cationorm shows good tolerability on human HCE-2 corneal epithelial cell cultures. Exp. Eye Res. 120:82-89, 2014.

65. Aragona, P., Papa, V., Micali, A., Santocono, M., and Milazzo, G. Long term treatment with sodium hyaluronatecontaining artificial tears reduces ocular surface damage in patients with dry eye. Br. J. Ophthalmol. 86:181-184, 2002.

66. Neuman, M.G., Nanau, R.M., Oruna, L., and Coto, G. In vitro anti-inflammatory effects of hyaluronic acid in ethanol- 
induced damage in skin cells. J. Pharm. Pharm. Sci. 14:425437, 2011.

67. Frey, H., Schroeder, N., Manon-Jensen, T., Iozzo, R.V., and Schaefer, L. Biological interplay between proteoglycans and their innate immune receptors in inflammation. FEBS J. 280:2165-2179, 2013.

68. Scheibner, K.A., Lutz, M.A., Boodoo, S., Fenton, M.J., Powell, J.D., and Horton, M.R. Hyaluronan fragments act as an endogenous danger signal by engaging TLR2. $J$. Immunol. 177:1272-1281, 2006.

69. Itano, N. Simple primary structure, complex turnover regulation and multiple roles of hyaluronan. J. Biochem. 144:131137, 2008.

70. Troiano, P., and Monaco, G. Effect of hypotonic $0.4 \%$ hyaluronic acid drops in dry eye patients: a cross-over study. Cornea. 27:1126-1130, 2008.

71. Liang, H., Brignole-Baudouin, F., Rabinovich-Guilatt, L., Mao, Z., Riancho, L., Faure, M.O., Warnet, J.M., Lambert,
G., and Baudouin, C. Reduction of quaternary ammoniuminduced ocular surface toxicity by emulsions: an in vivo study in rabbits. Mol. Vis. 14:204-216, 2008.

Received: May 18, 2015 Accepted: October 19, 2015

Address correspondence to: Dr. Jean-Sébastien Garrigue Novagali Innovation Center Santen SAS 1, rue Pierre Fontaine Bâtiment Genavenir IV F-91058 Evry Cedex France

E-mail: jean-sebastien.garrigue@ santen.fr 